INDEPENDENT JOURNAL OF MANAGEMENT \& PRODUCTION (IJM\&P)

http://www.ijmp.jor.br

v. 11, n. 7, November - December 2020

ISSN: 2236-269X

DOI: 10.14807/ijmp.v11i7.1015

\title{
UTILIZATION OF GREY MADM METHODOLOGY IN TECHNOLOGY ATTRACTIVENESS ASSESSMENT: A CASE STUDY IN UPSTREAM INDUSTRY
}

\author{
Azadeh Dabbaghi \\ Research Institute of Petroleum Industry (RIPI), Iran \\ E-mail:dabbaghi@ut.ac.ir
}

Submission: 8/19/2019

Revision: 9/18/2019

Accept: 1/30/2020

\section{ABSTRACT}

Technology assessment help managers to accomplish an overall evaluation of technologic options and to identify investment priorities. Making such priority has become of great importance owing to ever-increasing costs of technological research and development and resource scarcity. Technology Attractiveness Assessment, as a primary step of Technology assessment process, has been considered in this paper. Based on the multi-criteria decision-making approach and because of the inherent uncertainty in the preference information on attributes, a Grey-MADM based methodology has been utilized in this paper to assess the technology attractiveness and rank the upstream industry technological options. Its application to a real case problem has been described step by step. The results of the case study showed that "Nano Coating for Drilling Tools", "Petroleum Systems Model Building" and "Integrated Asset Modelling" are the most attractive upstream technologies.

Keywords: Technology Attractiveness Assessment, Grey Theory, Grey Possibility Degree, Upstream Oil and Gas Industry 
DOI: 10.14807/ijmp.v11i7.1015

\section{INTRODUCTION}

The enterprise-level technology assessment process is usually performed on key technologies, i.e. technologies that play an essential role in achieving corporate strategic goals. In the field of technology management, the technology assessment process is divided into two major parts: technology auditing and technology attractiveness assessment; in this paper, the technology attractiveness assessment is studied.

The technology attractiveness assessment process is an intellectual framework and an appropriate tool for a better understanding of the state of the technology. A continuous process, which is an essential part of enterprise technology management, supports the enterprise competitiveness with reinforcing input information in the strategic process of choosing the best technology. The results of the recent researches indicate the technology management consultants and academic researchers' deep attention in this field (TRAN; DAIM, 2008).

The emphasis is on the fact that the process of technology attractiveness assessment is not only for high-technology companies but also for all companies that use technology to deliver their products and services. Such companies must assess the technology of the product and the process used in the value chain and also the other technologies that contribute to the development of technological capabilities.

The importance of assessing enterprise-level technology attractiveness can be found in determining the research and technological development policies, attracting new technology, development of existing technology in the enterprise, deciding on purchasing or manufacturing technology, and determining the level of optimal investment in technology. Such an assessment also contributes to determining the value chain and market benefits.

Various methods have been presented for assessing technology, so far. In this paper, a step by step methodology has been provided for the technology attractiveness assessment using grey theory which is appropriate to the analysis of incomplete data under uncertainty situation.

\section{Technology Assessment}

The concept of technology assessment was first introduced in the late '60s with the establishment of the Office of Technology Assessment (OTA) in the United States. The purpose of the technology assessment at that time was to understand the social, economic, political, moral, and the other possible implications arising from introducing a new technology or developing an existing technology that was used to assist US public policy. 
DOI: 10.14807/ijmp.v11i7.1015

From the beginning of introducing the concept of technology assessment, the views of executive directors of industries and businesses were attracted to it. Coats \& Fabian (1982), concluded that many companies regard the technology assessment as an attempt to predict the impact of external environment on their activities, rather than predicting the consequences of their activities on the outside environment.

Maloney (1982) indicated that the concept of the enterprise-level technology assessment is different from the public-level technology assessment. The research revealed that the purpose of the private sector from technology assessment studies was to maximize the corporate profits in the short and medium time. In contrast, the public sector in a long-term perspective regards the technological implications on the dimensions of society.

\section{Technology Attractiveness Assessment}

At the enterprise level and from the perspective of the executive directors in the field of technology and R \& D management, the technology attractiveness assessment means the determination of related technology attractiveness of the products and processes that the enterprise is using or intends to use it in the near future. The technology attractiveness assessment is used to increase the effectiveness of financial and operational analyses of the various technology options, the selection, and acquisition of critical technologies and strategic planning of enterprise technology (TRAN; DAIM, 2008).

In developing a technology strategy based on the technology portfolio analysis approach, technology attractiveness assessment is one of the key dimensions of the attractiveness-capability matrix that has been used by the various researchers in the field of academic researches as well as leading technology advisors to develop the enterprise's technological capabilities (VITTORIO, 2001). Azzone and Manizni (2008) showed that according to the purpose of the application, the type of application and study context (industry level, corporate level, the section of private and public R \& D companies, specific industries, etc.), there are various methods to assess the attractiveness of technology.

Technology assessment has been of great importance to researchers and managers of public and private sectors since 1969. Different TA methods have been developed and utilized over the past four decades. Several studies summarized and categorized these techniques and methods (KRICHMAYER et al., 1975; HENRIKSEN, 1997; TRAN; DAIM 2008). A list of technology assessment methods is shown in table 1 Based on the classification conducted by Tran and Daim (2008). 
DOI: 10.14807/ijmp.v11i7.1015

Table 1: technology assessment techniques

\begin{tabular}{|l|c|c|}
\hline Technology assessment method & $\begin{array}{l}\text { Usage in public } \\
\text { decision-making } \\
\text { domain }\end{array}$ & $\begin{array}{l}\text { business and non- } \\
\text { governmental uses }\end{array}$ \\
\hline Structural modeling and system dynamics & $\nabla$ & \\
\hline Impact analysis & $\square$ & \\
\hline Scenario analysis & $\square$ & \\
\hline Risk assessment & $\nabla$ & $\square$ \\
\hline Decision analysis & $\nabla$ & \\
\hline Environmental concerns and integrated TA & $\square$ & $\square$ \\
\hline Emerging technologies & $\square$ & $\square$ \\
\hline Cost-benefit analysis methods & & $\square$ \\
\hline Decision analysis & & $\square$ \\
\hline Measures for technology & & $\square$ \\
\hline Roadmapping & & $\square$ \\
\hline Scenarios and Delphi & & $\square$ \\
\hline Surveying and information monitoring & & \\
\hline
\end{tabular}

As shown in table 1, decision analysis method has been applied in a wide range of technology assessment problems in both the private and public sectors.

\section{Technology Attractiveness Assessment Using Multi-Criteria Decision Making}

By adopting the "Multi-Criteria Decision Making" approach in technology attractiveness assessment, the process of assessing the technological options based on the various attributes can be fulfilled in a systematic methodology. Different technological options based on the decision-making attributes are assessed compared with each other and within the framework of the proposed method.

Nowadays, the achievement of competitive advantages and the effectiveness of production enforce the companies and businesses to choose one or more identified technologies to develop the technological capabilities and technology portfolio, due to the time, financial, and management limitations. The results of the technology attractiveness assessment are considered as the key inputs of the strategic process of choosing technology.

Some researches utilized AHP as a multi criteria decision making technique for assessing the attractiveness or selecting the appropriate technologies. Prasad and Somasekhard (1990) used a combination of the Delphi method and AHP for choosing the technologies in Indian telecommunications. Raju et al. (1995) applied AHP to rank five technology alternatives in toilet soap-making. Aloini et al. (2018) applied an Intuitionistic Fuzzy multi-criteria group decision making with the TOPSIS method for technology assessment in the advanced underwater system sector. 
DOI: 10.14807/ijmp.v11i7.1015

Many attributes are adopted and utilized in the literature for assessing the technology attractiveness. Jolly (2003) collected a number of criteria identified in the literature and classified them into the four groups, as shown in table 2.

Table 2: Technology Attractiveness Assessment attributes

\begin{tabular}{|c|c|}
\hline Competition factors & Market factors \\
\hline Number of stake-holders & Market volume opened by technology \\
\hline Competitors' level of involvement & Span of applications opened by technology \\
\hline Competitive intensity & Market sensitivity to technical factors \\
\hline Impact of technology on competitive issues & Technical factors \\
\hline Barriers to copy or imitation & Position of the technology in its own life-cycle \\
\hline Dominant design & Potential for progress \\
\hline Other criteria & Performance gap vis- $a^{`}$-vis alternative technologies \\
\hline Societal stakes & Threat of substitution technologies \\
\hline Public support for the development & Ability to transfer the technology from one unit to another \\
\hline
\end{tabular}

From the strategic perspective, some researches have also indicated that the use of high technology significantly increases the enterprise's competitive position (ESBATI et al., 2009). Therefore, the impact of technology on achieving the enterprise goals, changing the conditions and creating compatibility and ultimately creating competitive advantage, is an essential factor in determining the attractiveness of the technology (ARASTI, 2001).

In the past years, the approaches based on fuzzy theory have been much applied for multi-criteria decision-making problems (WANG, 2005), especially in the technology attractiveness assessment which is under uncertainty situation in real-world cases. Prabhu and Vizayakumar (2001) utilized a multi-criteria decision-making approach in the case of assessing iron-making technologies considering non-crisp (fuzzy) values. Jakubczyk and Kamiński (2017) introduced fuzziness into the decision-making process in health technology assessment. Chuu (2009) developed a fuzzy multiple attribute group decision-making to improving advanced manufacturing technology selection process. Tavana and Sodenkamp (2010) applied a fuzzy multi-criteria decision analysis model to advanced technology assessment at Kennedy Space Center.

Another method that enables the mathematical analysis and evaluation of systems with uncertain information is the grey systems theory which is explained in section 5.

\section{Grey Systems Theory}

\subsection{Grey Systems Theory and Fuzzy Set Theory}

The grey system theory was introduced by Deng in the early 1980s for the use in uncertainty situations with incomplete data and inadequate information (DENG, 1989). In many systems, such as social, economic, industrial systems, etc., the naming is because of the 
DOI: 10.14807/ijmp.v11i7.1015

branches and issues that are being investigated in these systems. Accordingly, "grey systems" are based on the color of the subjects under investigation. For example, in the theory of control, the darkness of colors indicates the amount of information and data clarity. One of the best examples is the "black box".

This term refers to a box which is entirely encoded and unknown to all its internal relations and structures. Here, the word "black" represents the unknown information. White is used for well-known information and "grey" for the information that is partly known and partly unknown. Accordingly, systems with known information are called the "white system", the systems with unknown information are called the "black system", and systems with partly known and partly unknown information are called "grey system" (LI; LIU, 2008).

The inherent uncertainty in the various fields such as production, technology, industrial management, etc. is rooted in two types of uncertainty. The first type of uncertainty, "stochastic uncertainty", is due to the random nature of the problem, which is described using statistics and probabilities, and patterns and statistical distribution functions. The study of this aspect of phenomena is based on high volume samples and considering the assumption that these samples follow a specific pattern called probability distribution (LIU; LIN, 2006).

The second type of uncertainty, "recognitive uncertainties", is due to the inherent complexity of the phenomenon and the lack of complete information about it (DENG, 1985). In order to describe and study this aspect of phenomena, the grey systems theory has been developed as the extension of fuzzy theory in incomplete information situation. The advantage of grey systems theory on the fuzzy set theory is that the grey theory involves fuzzy situations (DENG, 1989).

In other words, grey systems theory can work effectively in fuzzy situations. The use of fuzzy set theory requires the recognition of the corresponding membership function based on the experts' experience. However, the grey theory works without such a requirement, also based on the available information range (LIU; LIN, 2006). Grey system theory has been applied to various areas such as grey decision, grey control, and grey prediction (LI et al., 2005). The "grey possibility degree" method is considered in the grey decision area and is more appropriate for solving many decision-making problems in uncertainty situations, than the other methods (TSENG, 2009).

As indicated in section 1, the enterprises should be able to deal with the uncertainties in the attractiveness assessment of technologies and process of determining the relative impact 
DOI: 10.14807/ijmp.v11i7.1015

of new technologies on competitiveness, effectiveness, and efficiency of their activities. Also, there is not complete information available to decision-makers (recognitive uncertainties) to predict the functional characteristics of new technologies, especially emerging new technologies and the consequences of their use in the enterprise; therefore, the " grey possibility degree " technique has been used as one of the most widely used and efficient techniques among grey systems theory to assess the technology attractiveness and rank the technological options of the enterprise.

\subsection{Grey Number and Possibility Degree}

\subsubsection{Grey Set and Grey Number}

A grey set $\mathrm{G}$ of $\mathrm{X}$ (universal set $X=R$ ) is defined by its two mappings $\bar{\mu}_{G}(x)$ and $\underline{\mu}_{G}(x)$. Where $\bar{\mu}_{G}(x): x \rightarrow[0.1]$ and $\underline{\mu}_{G}(x): x \rightarrow[0.1] ; \bar{\mu}_{G}(x) \geq \underline{\mu}_{G}(x), x \in X$ and $\underline{\mu}_{G}(x)$ is the lower membership function and $\bar{\mu}_{G}(x)$ is the upper membership function in G grey set (SU et al., 2016).

A grey number can be defined as a number with uncertain information. There will be a numerical interval expressing it. This numerical interval will contain uncertain information. Generally, the grey number is written as $\otimes G \in[\underline{\mu} . \bar{\mu}]$.

\subsubsection{Grey possibility Degree}

in order to compare two grey numbers $\otimes G_{1} \in\left[\underline{G_{1}} \cdot \bar{G}_{1}\right] \cdot \otimes G_{2} \in\left[\underline{G}_{2} \cdot \bar{G}_{2}\right]$, the grey possibility degree (GPD) can be utilized as follows (SHI et al.,2005):

$P\left\{\otimes G_{1} \leq \otimes G_{2}\right\}=\frac{\max \left(0 \cdot L^{*}-\max \left(0 \cdot \bar{G}_{1}-\underline{G_{2}}\right)\right)}{L^{*}}$. where $L^{*}=L\left(\otimes G_{1}\right)+L\left(\otimes G_{2}\right)$.

The comparison between $\otimes G_{1}$ and $\otimes G_{2}$ is based on the following four possible cases: If $\underline{G_{1}}=\underline{G}_{2}$ and $\bar{G}_{1}=\bar{G}_{2}$, then $\otimes G_{1}$ is equal to $\otimes G_{2}$, then $P\left\{\otimes G_{1} \leq \otimes G_{2}\right\}=0.5$. If $\underline{G_{2}}>\bar{G}_{1}$, then $\otimes G_{2}$ is larger than $\otimes G_{1}$, then $P\left\{\otimes G_{1} \leq \otimes G_{2}\right\}=1$. If $\bar{G}_{2}<\underline{G}_{1}$, then $\otimes G_{2}$ is smaller than $\otimes G_{1}$, then $P\left\{\otimes G_{1} \leq \otimes G_{2}\right\}=0$.

If there is an intercrossing part in them, when $P\left\{\otimes G_{1} \leq \otimes G_{2}\right\}>0.5$, then we say that $\otimes G_{2}$ is larger than $\otimes G_{1}$. When $P\left\{\otimes G_{1} \leq \otimes G_{2}\right\}<0.5$, then we say that $\otimes G_{2}$ is smaller than $\otimes G_{1}$. 
DOI: 10.14807/ijmp.v11i7.1015

The length of a grey number $(L(\otimes G))$ and the basic operation laws of grey numbers can be calculated based on the definitions presented by Moore (1966) and Wu et al.,(2005).

\section{Assessing Technology Attractiveness Utilizing GPD}

This paper follows the general approach proposed by Li et al. (2007) and followed by Baskaran et al. (2012). This method is very suitable for solving the multi-criteria decisionmaking problem in an uncertain environment. Assume that $T=\left\{T_{1}, T_{2}, \ldots, T_{m}\right\}$ is a discrete set of $\mathrm{m}$ possible corporate technologies which is regarded as decision alternatives. $Q=\left\{Q_{1}, Q_{2}, \ldots, Q_{n}\right\}$ is a set of $\mathrm{n}$ additively independent attributes for assessing the attractiveness of technology. By adopting the Grey possibility degree approach, assessing and ranking of the alternatives can be performed utilizing the following steps:

- Step 1: calculate the weights of the attributes:

In order to identify the importance weights of technology attractiveness assessment criteria, a group of k decision-makers (experts) identify $\otimes w=\left\{\otimes w_{1} . \otimes w_{2} \ldots . . \otimes w_{n}\right\}$ as the vector of $\mathrm{n}$ attribute weights. Each attribute weight can be calculated as follows

$$
\otimes w_{j}=\sqrt[k]{\otimes w_{j}^{1} \times \otimes w_{j}^{2} \times \cdots \times \otimes w_{j}^{k}}
$$

Where $\otimes w_{j}^{k}(j=1,2, \ldots, n)$ is the attribute weight of $K_{\text {th }}$ decision maker which is identified by grey number $\otimes w_{j}^{k}=\left[\underline{w}_{j}^{k}, \bar{w}_{j}^{k}\right]$ based on table 3 (LI et al., 2007; DABBAGHI et al., 2009).

Table 3: the 7 scale expression of experts' preferences on the importance weight of attributes

\begin{tabular}{|c|c|c|c|c|c|c|c|}
\hline scale & $\begin{array}{c}\text { Very Low } \\
\text { VL }\end{array}$ & $\begin{array}{c}\text { Low } \\
\text { L }\end{array}$ & $\begin{array}{c}\text { Medium Low } \\
\text { ML }\end{array}$ & $\begin{array}{c}\text { Medium } \\
\text { M }\end{array}$ & $\begin{array}{c}\text { Medium High } \\
\text { MH }\end{array}$ & $\begin{array}{c}\text { High } \\
\text { H }\end{array}$ & $\begin{array}{c}\text { Very High } \\
\text { VH }\end{array}$ \\
\hline$\otimes w$ & {$[0.01,0.1]$} & {$[0.1,0.3]$} & {$[0.3,0.4]$} & {$[0.4,0.6]$} & {$[0.6,0.7]$} & {$[0.7,0.9]$} & {$[0.9,1.0]$} \\
\hline
\end{tabular}

In order to decrease the number of attributes and facilitate the decision-making process, the less important attributes in which $w_{j}(\bar{G})<\otimes w^{M H}(\underline{G})$ can be deleted from the set of $\mathrm{n}$ attributes. $\otimes w^{M H}(\underline{G})$ is the lower limit of the "Medium High " scale according to Table 3.

- Step 2: Establish the grey decision matrix (MEHREGAN et.al., 2014; RAJAPRASAD, 2018):

$D=\left[\begin{array}{cccc}\otimes G_{11} & \otimes G_{12} & \ldots & \otimes G_{1 n} \\ \otimes G_{21} & \otimes G_{22} & \ldots & \otimes G_{2 n} \\ \vdots & \vdots & & \vdots \\ \otimes G_{m 1} & \otimes G_{m 2} & \ldots & \otimes G_{m n}\end{array}\right]$ 
DOI: 10.14807/ijmp.v11i7.1015

Where $\otimes G_{i j}$ are the ratings of the $\mathrm{i}_{\text {th }}$ technology with respect to the $\mathrm{j}_{\mathrm{th}}$ attribute. These ratings are expressed in the form of grey numbers by the 1-7 linguistic scale as shown in table 4.

Table 4: the 7 scale expression of experts' ratings about alternatives respect to the attributes

\begin{tabular}{|c|c|c|c|c|c|c|c|}
\hline scale & $\begin{array}{c}\text { Very poor } \\
\text { VP }\end{array}$ & $\begin{array}{c}\text { poor } \\
\text { P }\end{array}$ & $\begin{array}{c}\text { Medium poor } \\
\text { MP }\end{array}$ & $\begin{array}{c}\text { Medium } \\
\text { M }\end{array}$ & $\begin{array}{c}\text { Medium good } \\
\text { MG }\end{array}$ & $\begin{array}{c}\text { good } \\
\text { G }\end{array}$ & $\begin{array}{c}\text { Very good } \\
\text { VG }\end{array}$ \\
\hline$\otimes G$ & {$[0,1]$} & {$[1,3]$} & {$[3,4]$} & {$[4,5]$} & {$[5,6]$} & {$[6,9]$} & {$[9,10]$} \\
\hline
\end{tabular}

- Step 3: Calculate the weighted normalized grey decision matrix

$$
D^{*}=\left[\begin{array}{ccccc}
\otimes T_{11} & \bigotimes T_{12} & \cdots & \otimes T_{1 n} \\
\otimes T_{21} & \bigotimes T_{22} & \cdots & \otimes T_{2 n} \\
\vdots & \vdots & & \ddots & \vdots \\
\otimes T_{m 1} & \bigotimes T_{m 2} & \cdots & \otimes T_{m n}
\end{array}\right]
$$

Where $\otimes T_{i j}=\otimes G_{i j}^{*} \times \otimes w_{j}$, in which $\otimes G_{i j}^{*}$ is calculated as follows (MEHREGAN et.al., 2014) based on the attribute type:

$$
\otimes G_{i j}^{*}=\left\{\begin{array}{lr}
{\left[\frac{G_{i j}}{G_{j}^{\text {max }}} \cdot \frac{\bar{G}_{i j}}{G_{j}^{\text {max }}}\right]} & \text {.for a benefit attribute } \\
{\left[\frac{G_{j}^{\text {min }}}{\bar{G}_{i j}} \cdot \frac{G_{j}^{\text {min }}}{G_{i j}}\right]} & \text {.for a cost attribute }
\end{array}\right.
$$

In which $G_{j}^{\max }=\max _{1 \leq i \leq m}\left\{\bar{G}_{i j}\right\}$ and $G_{j}^{\min }=\min _{1 \leq i \leq m}\left\{\underline{G}_{i j}\right\}$.

In the calculated weighted normalized grey decision matrix, the attribute weights are considered in the decision matrix values. Furthermore, the normalization process guarantees that the ranges of normalized grey numbers $\otimes G_{i j}^{*}$ are between 0 and 1 .

- $\quad$ Step 4: Define a Reference technology

For the set of technology alternatives, an assumptive technology as the best alternative can be obtained by:

$$
T_{0}=\left\{\left[\max _{1 \leq i \leq m} T_{i 1} \cdot \max _{1 \leq i \leq m} \bar{T}_{i 1}\right] \cdot\left[\max _{1 \leq i \leq m} T_{i 2} \cdot \max _{1 \leq i \leq m} \bar{T}_{i 2}\right] \ldots\left[\max _{1 \leq i \leq m} T_{i n} \cdot \max _{1 \leq i \leq m} \bar{T}_{i n}\right]\right\}
$$

- Step 5: determine the ranking of technologies

The grey possibility degree between each alternative technology and the reference technology is calculated based on the definitions presented in section 5-2-2. The less the value calculated for $P\left\{T_{i} \leq T_{0}\right\}$ the ranking of the $\mathrm{j}$ th technology is better and vice versa. 
DOI: 10.14807/ijmp.v11i7.1015

$$
P\left\{T_{i} \leq T_{0}\right\}=\frac{1}{n} \sum_{j=1}^{n} P\left\{\otimes T_{i j} \leq \otimes T_{j}^{\text {max }}\right\}
$$

\section{Application and Analysis: Upstream industry in Iran}

In this part of the paper, the application of the proposed methodology (described in section 6) to the upstream industry is described step by step. National Iranian Oil Company as the only public company in the upstream oil industry, is headquartered in the research and technological development. So, the assessment and selection of attractive technologies and then preparation of a roadmap to attain the selected technologies, as one of the missions of this company, has been adopted to satisfy the technical and operational needs of the leading company and its subsidiaries.

In order to assess the technology attractiveness, a set of technologies were considered according to the upstream value chain and the operating conditions of this industry, as shown in table 5 .

Table 5: the list of attractive upstream technologies as the case problem alternatives

\begin{tabular}{|cl|}
\hline Alternative & Technologies \\
\hline $\mathrm{T}_{1}$ & Full Wave Inversion \\
$\mathrm{T}_{2}$ & Seismic Sequence Stratigraphy \\
$\mathrm{T}_{3}$ & Wide Azimuth Acquisition Time Laps \\
$\mathrm{T}_{4}$ & Walk Away and 3D Vertical Seismic Profile (VSP) \\
$\mathrm{T}_{5}$ & Petroleum Systems Model Building \\
$\mathrm{T}_{6}$ & Coupled Fluid-Structure Interaction Analysis \\
$\mathrm{T}_{7}$ & Cement And Drilling Fluid Additives \\
$\mathrm{T}_{8}$ & Nano Coating for Drilling Tools \\
$\mathrm{T}_{9}$ & Acidizing Methods and Additives \\
$\mathrm{T}_{10}$ & Hydraulic Fracturing \\
$\mathrm{T}_{11}$ & Integrated Asset Modelling \\
$\mathrm{T}_{12}$ & Automated History Matching and Data Integration \\
$\mathrm{T}_{13}$ & Smart Well \\
$\mathrm{T}_{14}$ & Water Alternating Gas (Wag) Injection \\
$\mathrm{T}_{15}$ & Tight Core SCAL Analysis \\
$\mathrm{T}_{16}$ & Integrated Fracture Network Modelling using Seismic and Dynamic Data \\
$\mathrm{T}_{17}$ & Enhanced Oil Recovery Pilot Design \\
$\mathrm{T}_{18}$ & Well Production Enhancement \\
\hline
\end{tabular}

The attributes for the technology attractiveness assessment were collected based on the literature review presented in section 4 and were customized and approved based on the upstream experts' opinions and results are shown in Table 6. These experts were ten experienced managers and researchers in the upstream petroleum industry of the country, familiar with the operational issues and the process of technology management. 
Table 6: the set of attributes

\begin{tabular}{|ll|c|}
\hline \multicolumn{2}{|c|}{ Attributes } & Attribute nature \\
\hline $\mathrm{Q}_{1}$ & Up-to-dateness & \\
$\mathrm{Q}_{2}$ & Performance Vis-a -Vis other technologies & Technical \\
$\mathrm{Q}_{3}$ & Potential for transfer and development of the related technologies & \\
\hline $\mathrm{Q}_{4}$ & Span of application and demand level of stakeholders & Competition \\
$\mathrm{Q}_{5}$ & Estimated development costs & \multirow{2}{*}{ Market } \\
\hline $\mathrm{Q}_{6}$ & Impact of technology on quality and differentiation & \\
$\mathrm{Q}_{7}$ & Potential for Commercialization & \\
\hline
\end{tabular}

- Step 1

The experts' opinions about the significance of the attributes were collected. So, the calculations related to the determination of weights were conducted using equation 12; the results are presented in Table 7.

Table 7: calculated attribute weights based on the experts' opinions

\begin{tabular}{|cccccccc|}
\hline Decision Makers & $\mathrm{Q} 1$ & $\mathrm{Q} 2$ & $\mathrm{Q} 3$ & $\mathrm{Q} 4$ & $\mathrm{Q} 5$ & $\mathrm{Q} 6$ & $\mathrm{Q} 7$ \\
\hline $\mathrm{k}_{1}$ & $\mathrm{MH}$ & $\mathrm{H}$ & $\mathrm{MH}$ & $\mathrm{MH}$ & $\mathrm{M}$ & $\mathrm{M}$ & $\mathrm{L}$ \\
$\mathrm{k}_{2}$ & $\mathrm{H}$ & $\mathrm{VH}$ & $\mathrm{MH}$ & $\mathrm{H}$ & $\mathrm{MH}$ & $\mathrm{L}$ & $\mathrm{ML}$ \\
$\mathrm{k}_{3}$ & $\mathrm{MH}$ & $\mathrm{H}$ & $\mathrm{M}$ & $\mathrm{VH}$ & $\mathrm{MH}$ & $\mathrm{M}$ & $\mathrm{M}$ \\
$\mathrm{k}_{4}$ & $\mathrm{MH}$ & $\mathrm{VH}$ & $\mathrm{MH}$ & $\mathrm{M}$ & $\mathrm{H}$ & $\mathrm{L}$ & $\mathrm{ML}$ \\
$\mathrm{k}_{5}$ & $\mathrm{MH}$ & $\mathrm{H}$ & $\mathrm{MH}$ & $\mathrm{MH}$ & $\mathrm{M}$ & $\mathrm{M}$ & $\mathrm{L}$ \\
$\mathrm{k}_{6}$ & $\mathrm{M}$ & $\mathrm{VH}$ & $\mathrm{MH}$ & $\mathrm{H}$ & $\mathrm{MH}$ & $\mathrm{ML}$ & $\mathrm{M}$ \\
$\mathrm{k}_{7}$ & $\mathrm{MH}$ & $\mathrm{VH}$ & $\mathrm{H}$ & $\mathrm{H}$ & $\mathrm{MH}$ & $\mathrm{H}$ & $\mathrm{VH}$ \\
$\mathrm{k}_{8}$ & $\mathrm{M}$ & $\mathrm{VH}$ & $\mathrm{MH}$ & $\mathrm{H}$ & $\mathrm{VH}$ & $\mathrm{M}$ & $\mathrm{M}$ \\
$\mathrm{k}_{9}$ & $\mathrm{MH}$ & $\mathrm{VH}$ & $\mathrm{H}$ & $\mathrm{MH}$ & $\mathrm{M}$ & $\mathrm{H}$ & $\mathrm{VH}$ \\
$\mathrm{k}_{10}$ & $\mathrm{MH}$ & $\mathrm{H}$ & $\mathrm{MH}$ & $\mathrm{MH}$ & $\mathrm{M}$ & $\mathrm{M}$ & $\mathrm{L}$ \\
\hline$\otimes w_{j}$ & {$[0.56,0.70][0.81,0.96][0.59,0.72][0.64,0.79][0.54,0.70][0.33,0.54][0.29,0.50]$}
\end{tabular}

For all of the calculated attribute weights $w_{j}(\bar{G})>\otimes w^{M H}(\underline{G})$; so all of the attributes were considered as important attributes in the remaining steps.

\section{- Step 2}

The grey decision matrix was established as shown in Table 8. 
DOI: 10.14807/ijmp.v11i7.1015

Table 8: the Grey decision Matrix

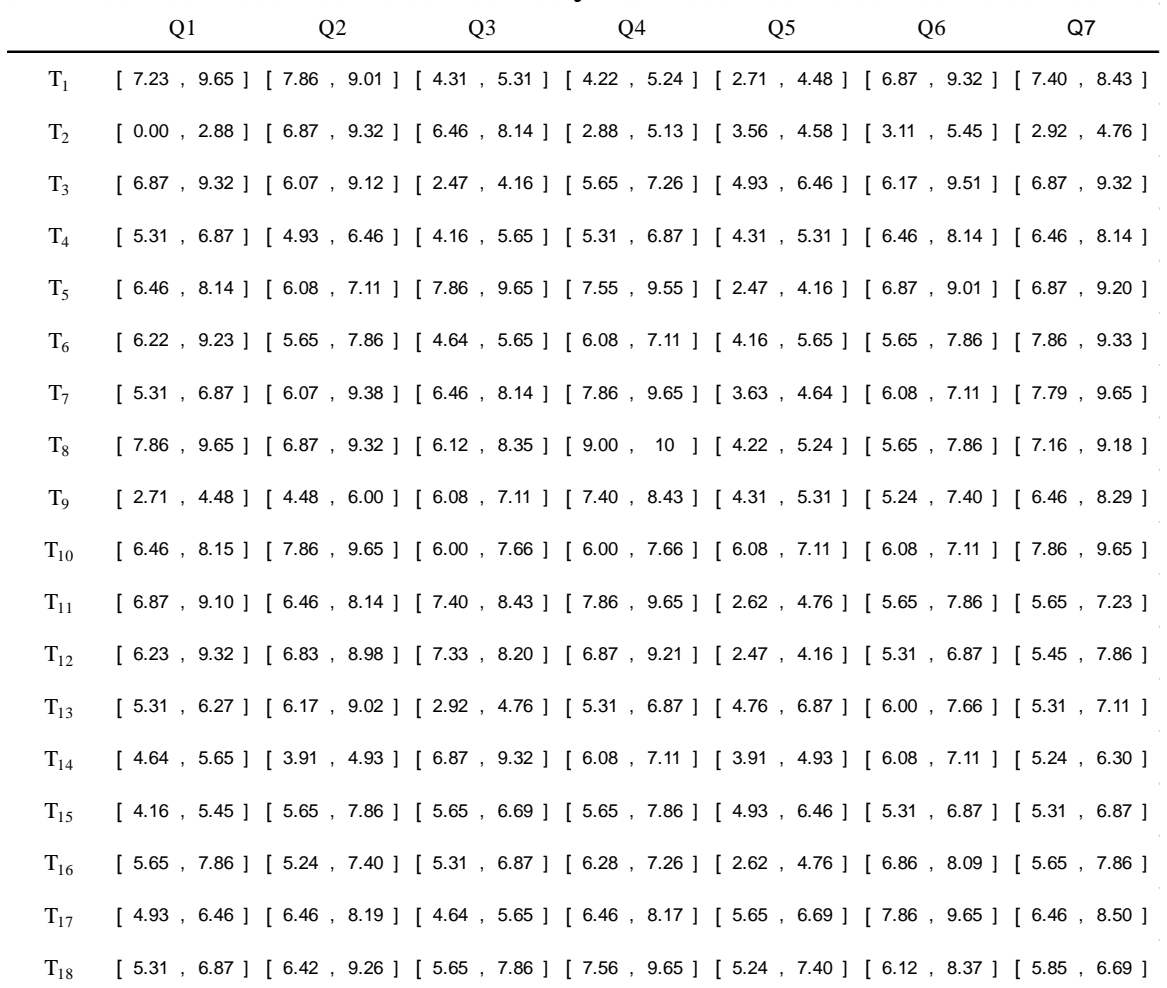

\section{- $\quad$ Step3}

The weighted normalized matrix was calculated as shown in Table 9.

Table 9: the weighted normalized matrix

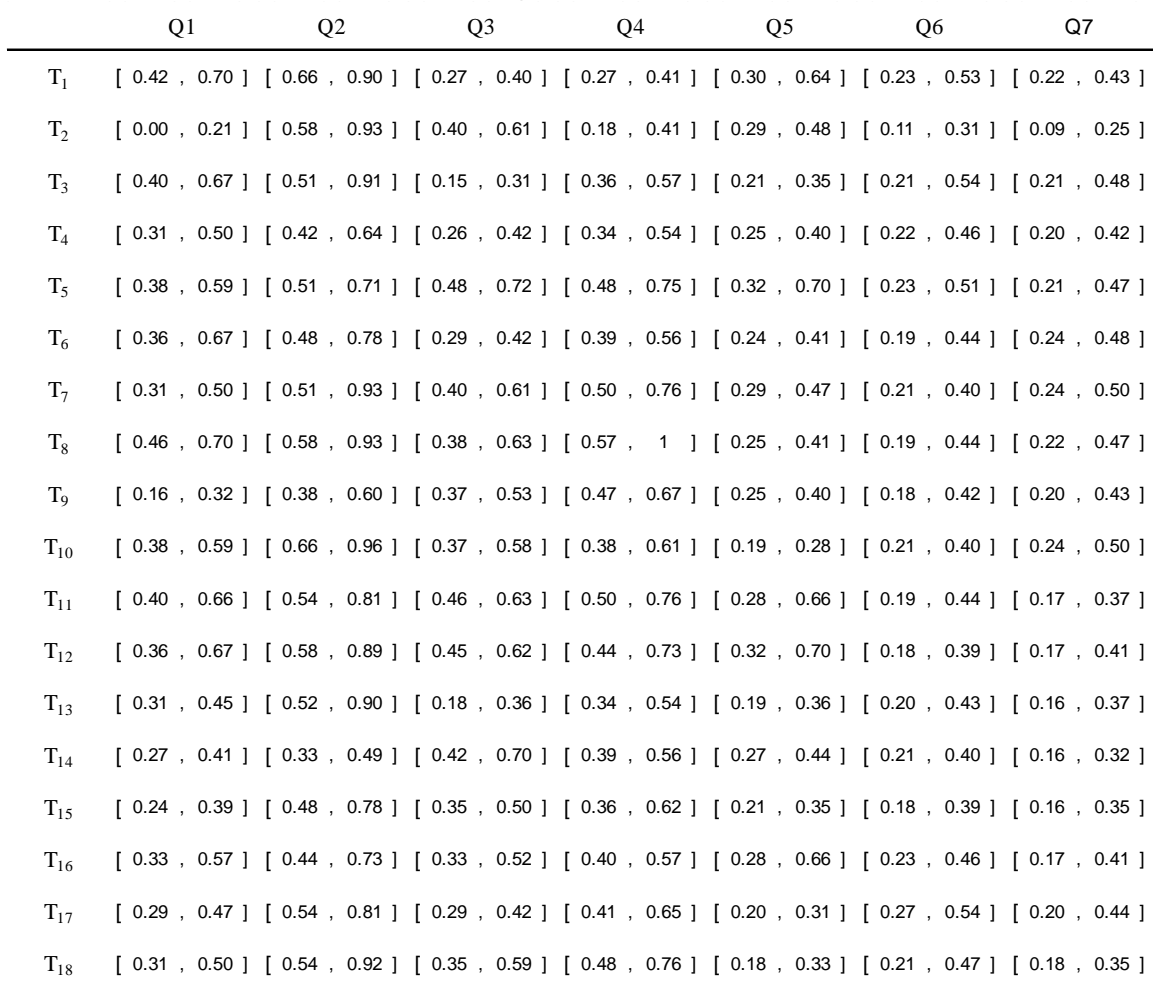

\section{- Step4}


DOI: 10.14807/ijmp.v11i7.1015

The reference technology can be defined as follows $T_{0}=\{[0.46 .0 .7] \cdot[0.66 .0 .96$ ]. [0.48 .0 .72 ] [ [0.57 .0.79 ]. [0.32 .0.7 ]. [0.27 .0.54 ]. [0.24 .0.5]\}

- Step5

The grey possibility degree between each alternative technology and the reference technology is calculated and results are shown in Table 10.

Table 10: the values of grey possibility degree calculated for each alternative technology

\begin{tabular}{|cc|cc|}
\hline & $P\left\{T_{i} \leq T_{0}\right\}$ & & $P\left\{T_{i} \leq T_{0}\right\}$ \\
\hline $\mathrm{i}=1$ & 0.684 & $\mathrm{i}=10$ & 0.736 \\
\hline $\mathrm{i}=2$ & 0.846 & $\mathrm{i}=11$ & 0.645 \\
\hline $\mathrm{i}=3$ & 0.753 & $\mathrm{i}=12$ & 0.646 \\
\hline $\mathrm{i}=4$ & 0.859 & $\mathrm{i}=13$ & 0.854 \\
\hline $\mathrm{i}=5$ & 0.624 & $\mathrm{i}=14$ & 0.840 \\
\hline $\mathrm{i}=6$ & 0.776 & $\mathrm{i}=15$ & 0.871 \\
\hline $\mathrm{i}=7$ & 0.687 & $\mathrm{i}=16$ & 0.773 \\
\hline $\mathrm{i}=8$ & 0.621 & $\mathrm{i}=17$ & 0.808 \\
\hline $\mathrm{i}=9$ & 0.832 & $\mathrm{i}=18$ & 0.755 \\
\hline
\end{tabular}

According to the calculated grey possibility degree for each alternative, the ranking order of technologies are shown in Table 11.

Table 11: the ranking results of the alternative technologies

\begin{tabular}{|cc|}
\hline Ranking & Technologies \\
\hline 1 & $\mathrm{~T}_{8}$ \\
2 & $\mathrm{~T}_{5}$ \\
3 & $\mathrm{~T}_{11}$ \\
4 & $\mathrm{~T}_{12}$ \\
5 & $\mathrm{~T}_{1}$ \\
6 & $\mathrm{~T}_{7}$ \\
7 & $\mathrm{~T}_{10}$ \\
8 & $\mathrm{~T}_{3}$ \\
9 & $\mathrm{~T}_{18}$ \\
10 & $\mathrm{~T}_{16}$ \\
11 & $\mathrm{~T}_{6}$ \\
12 & $\mathrm{~T}_{17}$ \\
13 & $\mathrm{~T}_{9}$ \\
14 & $\mathrm{~T}_{14}$ \\
15 & $\mathrm{~T}_{2}$ \\
16 & $\mathrm{~T}_{13}$ \\
17 & $\mathrm{~T}_{4}$ \\
18 & $\mathrm{~T}_{15}$ \\
\hline
\end{tabular}

\section{CONCLUSIONS}

Nowadays, the organizations with the aim of achieving the competitive advantage and production effectiveness have to assess the attractiveness of technologies and choose a limited 
DOI: 10.14807/ijmp.v11i7.1015

number of identified technologies due to the time, financial and managerial constraints. The identified attractive technologies can be considered as the critical inputs to the remainder strategic technology management process.

This paper applies the "Grey Possibility Degree" approach into a methodology for technology attractiveness assessment. The grey systems theory is appropriate for the assessment and analysis of systems under uncertainty situation. This methodology, which is explained in five steps, provides a systematic procedure for assessing a set of attractive technologies through a number of attributes based on the overall framework of "multi-criteria decision-making methods".

Finally, as a case study, the methodology has been utilized to assess the technology attractiveness in the upstream industry in Iran. A set of 18 upstream technologies were considered as alternatives. The experts' preferences and ratings about these alternatives were described by grey numbers to deal with the uncertainty inherent in their judgments. The calculations were accomplished based on the methodology and explained step by step.

The results showed that the most attractive upstream technologies are: 1 . Nano Coating for Drilling Tools, 2. Petroleum Systems Model Building, 3. Integrated Asset Modelling, 4. Automated History Matching and Data Integration, 5. Full Wave Inversion. These selected technologies in the case problem have been considered for the upstream technological capability assessments and further development.

\section{REFERENCES}

ALOINI, D.; DULMIN, R.; MININNO, V.; PELLEGRINI, L. AND FARINA, G. (2018) Technology assessment with IF-TOPSIS: An application in the advanced underwater system sector. Technological Forecasting and Social Change, v. 131, p. 38-48.

ARASTI, M. (2001) Selection of suitable Model for codifying technology strategy of the electricity industry, defining technologic strategies of Iran Electricity Industry project documents, Iran.

AZZONE, G.; MANZINI, R. (2008) Quick and dirty technology assessment: The case of an Italian Research Centre. Technological Forecasting and Social Change, v. 75, n. 8, p. 13241338.

BASKARAN, V.; NACHIAPPAN, S.; RAHMAN, S. , N. (2012) Indian textile suppliers' sustainability evaluation using the grey approach, International Journal of Production Economics, v. 135, n. 2, p. 647-658

CHUU, S. J. (2009) Selecting the advanced manufacturing technology using fuzzy multiple attributes group decision making with multiple fuzzy information. Computers \& industrial engineering, v. 57, n. 3, p. 1033-1042. 
INDEPENDENT JOURNAL OF MANAGEMENT \& PRODUCTION (IJM\&P)

http://www.ijmp.jor.br

v. 11, n. 7, November - December 2020

ISSN: 2236-269X

DOI: 10.14807/ijmp.v11i7.1015

COATES, V. T.; FABIAN, T. (1982) Technology assessment in industry: A counterproductive myth?. Technological Forecasting and Social Change, v. 22, n. 3-4, p. 331-341.

DABBAGHI, A.; MALEK, A. M.; AULIZADEH, A. R. (2010) Evaluating the quality of corporate mission statements. In Proceedings of the 6th international strategic management conference.

DENG, J. L. (1989) Introduction to grey system theory. Journal of Grey System, v. 1, n. 1, p. $1-24$.

DENG J. L. (1985) Special issue of grey system approach. Fuzzy Mathematics, v. 5, n. 2. ESBATI, H.; KARIMIYAN, A.; AGHAPOOR, A. (2009) Acquaintance with the basics and models of technology strategy. Defense Industries organization, In Persian.

HENRIKSEN, A. D. P. (1997) A technology assessment primer for the management of technology. International Journal of Technology Management, v. 13, n. 5, p. 615-638.

JAKUBCZYK, M.; KAMIŃSKI, B. (2017) Fuzzy approach to decision analysis with multiple criteria and uncertainty in health technology assessment. Annals of Operations

Research, v. 251, n. 1-2, p. 301-324

JOLLY, D. (2003) The issue of weightings in technology portfolio

management. Technovation, v. 23, n. 5, p. 383-391.

KRICHMAYER, L.; LINSTONE, H. A.; MORSCH, W. (1975) A Technol. Primer, IEEE.

LI, G. D.; YAMAGUCHI, D.; NAGAI, M. N. (2007) A grey-based decision-making approach to the supplier selection problem, Mathematical and Computer Modelling, v. 46, n. $3-4$, p. $573-581$

LI, G. D.; YAMAGUCHI, D.; NAGAI, M. (2005) New methods and accuracy improvement of GM according to Laplace transform. Journal of Grey System, v. 8, n. 1, p. 13-25.

LI, Q. X.; LIU, S. F. (2008) The foundation of the grey matrix and the grey input-output analysis. Applied Mathematical Modelling, v. 32, n. 3, p. 267-291.

LIU, S. AND LIN, Y. (2006) Grey information: theory and practical applications. Springer Science \& Business Media.

MALONEY JR, J. D. (1982) How companies assess technology. Technological Forecasting and Social Change, v. 22, n. 3-4, p. 321-329.

MEHREGAN, M. R.; JAFARNEJAD, A.; DABBAGHI, A. (2014) Technical Ranking of Oil Reservoirs for CO2 EOR by a GRA-based Methodology. Petroleum Science and Technology, v. 32, n. 21, p. 2529-2537.

MOORE, R. E. (1966) Interval analysis, v. 4. Englewood Cliffs, NJ: Prentice-Hall.

PRABHU, T. R.; VIZAYAKUMAR, K. (2001) Technology choice using FHDM: A case of iron-making technology. IEEE Transactions on Engineering Management, v. 48, n. 2, p. 209-222.

PRASAD, A.V.S.; SOMASEKHARA, N. (1990) The analytic hierarchy process for choice of technologies: an application. Technological Forecasting and Social Change, v. 38, n. 2, p. 151-158. 
DOI: 10.14807/ijmp.v11i7.1015

RAJAPRASAD, S. V. S. (2018) Selection of safety officers in an Indian construction organization by using grey relational analysis. Independent Journal of Management \& Production, v. 9, n. 1, p. 97-110.

RAJU, U. S.; RANGARAJ, N.; DATE, A. W. (1995) The influence of development perspectives on the choice of technology. Technological Forecasting and Social Change, v. 48, n. 1, p. 27-43.

SHI, J. R.; LIU, S. Y.; XIONG, W. T. (2005) A new solution for interval number linear programming. Systems Engineering-theory \& Practice, v. 2, p.16.

SU, C. M.; HORNG, D. J.; TSENG, M. L.; CHIU, A. S.; WU, K. J.; CHEN, H. P. (2016) Improving sustainable supply chain management using a novel hierarchical grey-DEMATEL approach. Journal of Cleaner Production, v. 134, p. 469-481.

TAVANA, M.; SODENKAMP, M. A. (2010) A fuzzy multi-criteria decision analysis model for advanced technology assessment at Kennedy Space Center. Journal of the Operational Research Society, v. 61, n. 10, p. 1459-1470.

TRAN, T. A.; DAIM, T. (2008) A taxonomic review of methods and tools applied in technology assessment. Technological Forecasting and Social Change, v. 75, n. 9, p. 13961405.

TSENG, M. L. (2009) A causal and effect decision-making model of service quality expectation using grey-fuzzy DEMATEL approach. Expert systems with applications, v. 36, n. 4, p. 7738-7748.

VITTORIO, C. (2001) R\&d Strategy \& Organisation: Managing Technical Change In Dynamic Contexts, v. 5. World Scientific.

WANG, Y. X. (2005) Application of fuzzy decision optimum model in selecting suppliers. The Journal of Science Technology and Engineering, v. 5, n. 15, p. 1100-1103.

WU, Q.; ZHOU, W.; LI, S.; WU, X. (2005) Application of grey numerical model to groundwater resource evaluation. Environmental Geology, v. 47, n. 7, p. 991-999. 